\title{
Equity in Social Work Employment: Opportunity and Challenge for Social Workers with
}

\author{
Disabilities in the United States \\ Lisa R. Kiesel ${ }^{\mathrm{a}}$, Sharyn Dezelar ${ }^{\mathrm{b}}$ \& Elizabeth Lightfoot $^{\mathrm{c}}$ \\ ${ }^{a}$ School of Social Work, St. Catherine University - University of St. Thomas, St. Paul, MN \\ ${ }^{b}$ School of Social Work, University of Minnesota, 1404 Gortner Avenue, St. Paul, MN 55108, \\ $U S A$
}

'School of Social Work, University of Minnesota, 105 Peters Hall, 1404 Gortner Avenue, St.

Paul, MN 55108, USA

This is an Accepted Manuscript of an article published by Routledge in Disability \& Society in March, 2019, available online: https://doi.org/10.1080/09687599.2018.1561354

It is deposited under the terms of the Creative Commons Attribution-NonCommercialNoDerivatives License (http://creativecommons.org/licenses/by-nc-nd/4.0/), which permits noncommercial re-use, distribution, and reproduction in any medium, provided the original work is properly cited, and is not altered, transformed, or built upon in any way. 


\begin{abstract}
People with disabilities in the United States have had low levels of employment for decades, and the employment rate of people with disabilities remains virtually unchanged despite efforts to improve employment participation. This qualitative inquiry explored barriers and opportunities related to employment for social workers with disabilities through understanding their experiences of seeking, obtaining, and maintaining social work employment in the United States. Five themes emerged: anticipation and experience of hiring discrimination, accommodation confusion, disappointment with the social work profession, disability makes one a better social worker, and this could be different (and better). Findings suggest implications for employers and the social work profession.
\end{abstract}

\title{
Points of interest
}

- The literature regarding employment of people with disabilities as professional social workers is extremely limited and not empirically based.

- This study explored barriers and opportunities related to employment for US social workers with disabilities through understanding their experiences of seeking, obtaining, and maintaining social work employment.

- Participants expressed belief that disability made them a better social worker.

- Challenges were experienced in the pursuit of employment, the need for accommodation, feeling accepted and supported, and being able to fulfill one's potential as a social worker. 
- This article contributes to varying degrees a sense of disappointment in the profession of social work and social work employment.

- However, there were also clear examples of what works and what could be better to ensure the inclusion of qualified social work professionals with disabilities in the workforce.

\section{Introduction}

People with disabilities in the United States have had low levels of employment for decades, with an employment rate of only $17.6 \%$ in 2016 compared to $65.3 \%$ for people without disabilities (U.S. Department of Labor 2017). Of those in the labor market, the unemployment rate for people with disabilities was $10.5 \%$ compared to $4.6 \%$ of workers without disabilities (U.S. Department of Labor 2017). Despite efforts to improve employment participation of people with disabilities in the United States such as the passage of the Americans with Disabilities Act (ADA) and the development of programs promoting the employment of people with disabilities, their employment rate remains virtually unchanged (Kaye, Jans, and Jones 2011). In the United States a person with a disability is defined as 'someone who (1) has a physical or mental impairment that substantially limits one or more "major life activities," (2) has a record of such an impairment, or (3) is regarded as having such an impairment' (U.S. Department of Labor, Office of Disability Employment Policy 2018b).

While there is a large body of research focusing on employment of people with disabilities (Burkhauser and Daly 2011; Cook 2006), there has been meager examination of the employment of people with disabilities in the field of social work. The purpose of this qualitative, descriptive inquiry was to explore barriers and opportunities related to employment 
for social workers with disabilities through understanding their experiences of seeking, obtaining, and maintaining social work employment.

\section{Background}

Although many social workers work with people with disabilities as clients (Whitaker, Weismiller, and Clark 2006) and there is a growing body of literature on best practices for working with people with disabilities (Mackelprang and Salsgiver 2015; Samat et al., 2009), the field has paid little attention to social workers with disabilities. There have been no systematic efforts to determine how many social workers have a disability, and the National Association of Social Workers' most recent workforce study of licensed social workers in the United States did not collect data on disability status (Salsberg et al. 2017). An early study found that just $2 \%$ of people with a Master of Social Work (MSW) degree reported having a disability (Mackelprang, Ray, and Hernandez-Peck 1996). Researchers have expressed concern that the field has not been welcoming to people with disabilities as professionals (Mackelprang 2010).

Most of the research related to social workers with disabilities in the profession has focused on postsecondary education, with numerous explorations of barriers that students with disabilities face (Flanagan, Benson, and Fovet 2014; Baron, Phillips, and Stalker 1996) and strategies for better supporting and accommodating students with disabilities (Neely-Barnes, McCabe, and Barns 2014). The literature regarding employment of people with disabilities as professional social workers is limited and not empirically based. Most of the attention has focused on either increasing understanding of the ADA, particularly in regards to reasonable accommodation (Neely-Barnes, McCabe, and Barnes 2014; O'Brien and Brown 2009; Pardeck 1998), or understanding the barriers that social workers with disabilities face (Orzolek- 
Kronner 2007; Sheridan, White, and Mounty 2010). After an exhaustive search, we found no studies examining the experiences of social workers with disabilities in the workforce.

There have been explorations of the employment of people with disabilities in general, and in other professional fields such as nursing (Matt 2008), education (Valle et al. 2004), and medicine (Mercer et al. 2003). Research about the employment of people with disabilities typically focuses on barriers to employment, including policy barriers, employment discrimination, and poor implementation of the ADA. While there has also been research that addresses disability-related issues correlated with experiences of people with disabilities in the workplace, such as the lower educational attainment, lower productivity rates due to higher absenteeism related to some types of disabilities, and ineffective vocational rehabilitation services (Cook 2006), the following review focuses on the barriers to employment.

\section{Policy barriers}

One of the key foci of research related to employment of people with disabilities is on the policy barriers to employment. This line of research typically focuses on why people with disabilities are not employed. Researchers have noted that in the United States both Social Security Disability Insurance and Supplemental Security Insurance, which provide important income supports for people with disabilities and qualify people with disabilities for healthcare coverage through Medicaid, define disability as being unable to work (Levy, Bruen, and $\mathrm{Ku}, 2013)$. As many people with disabilities need some of the benefits of these programs to survive, they are effectively trapped on these income support programs to retain their benefits (Stapleton et al. 2006; Burkhauser and Daly 2011; Kennedy and Blodgett 2012). Likewise, people with disabilities often have remained unemployed because they would not qualify for 
employer-sponsored insurance (Cook 2006). While there have been numerous federal attempts to help people with disabilities navigate this complex system or provide workarounds to this problem, these disincentives persist (Livermore and Goodman 2009). While the Medicaid expansion policies under the Affordable Care Act appeared to increase employment rates in states that expanded coverage (Hall et al. 2017), the Affordable Care Act no longer requires this partial policy solution (Sommers and Epstein 2013).

\section{Employment discrimination}

A second large focus of employment research regarding people with disabilities is the continued employment discrimination that they face in regards to recruitment, hiring, compensation, promotion, workplace opportunities, and termination. This line of research helps explain both the low employment rates of people with disabilities and the experiences of people with disabilities who are employed. Numerous studies demonstrate that people with all types of disabilities continue to experience wide-ranging discrimination in all aspects of employment (Fevre et al. 2013). Much of this has been attributed to negative attitudes or stigma that employers and coworkers hold, such as believing people with disabilities will not have the skills and experience to effectively perform work tasks, concerns about safety, and fear of the costs of accommodations (Kaye, Jans, and Jones 2011; Shier, Graham, and Jones 2009; Lengnick-Hall, Gaunt, and Kulkarni 2008; McLaughlin, Bell, and Stringer 2004; Scheid 2005; Wilson-Kovacs et al. 2008; U.S. Department of Labor, Office of Disability Employment Policy 2008). Studies have found that while employers may hold more positive global attitudes about people with disabilities, specific attitudes are less positive (Hernandez, Keys, and Balcazar 2000). People with disabilities have reported higher rates of ill-treatment than their non-disabled coworkers, 
experiencing 'othering,' having offensive comments made about them or their abilities, joking amongst coworkers about disabilities, being micro-managed at high rates, being given unmanageable workloads, and being pressured to work below their level of competence (Fevre et al. 2013; Mik-Meyer 2016b). Some research has found that stress related to workplace discrimination exacerbates some people's disabilities, further inhibiting their workplace experience (Foster and Fosh 2010). Additionally, coworkers and supervisors may view people with disabilities as 'less than' non-disabled employees, as people with disabilities experience infantilization by coworkers and managers: being referred to in child-like terms of 'small and cute,' using pet nicknames for disabled colleagues, and also desires to 'mother' the colleague with a disability (Mik-Meyer 2016a).

\section{Problems with the Americans with Disabilities Act}

As reducing workplace discrimination against people with disabilities is a key component of the ADA in the United States, there has been a considerable amount of research into its implementation. There has been much inquiry about why employment rates have not risen since its passage (Burkhauser and Daly 2011). The ADA requires disclosure of disability to receive an accommodation. Reasonable accommodations are defined in the ADA as:

modification or adjustment to a job, the work environment, or the way things are usually done during the hiring process. These modifications enable an individual with a disability to have an equal opportunity not only to get a job but successfully perform their job tasks to the same extent as people without disabilities. (U.S. Department of Labor, Office of Disability Employment Policy 2018a) 
People with disabilities have reported struggles with gaining needed ADA accommodations, both due to misunderstandings about the ADA and fears regarding perceptions of others if they asked for an accommodation (Foster and Fosh 2010). As people with disabilities experience workplace discrimination because of stigma (Wahl 1999), their fears are not unwarranted. Also, Kay, Jans, and Jones (2011) found that employers' fear of a future ADA lawsuit might dissuade them from hiring a person with a disability.

Recognizing the varied and layered challenges and barriers to employment for people with disabilities generally, and to some extent social workers with disabilities specifically, the purpose of this study was to examine the professional experiences and trajectories of a sample of social work professionals in the Midwest of the United States with a wide variety of disability.

\section{Methods}

This study was part of a broader qualitative exploration of the experiences of social workers with disabilities in both field education and employment. This study was part of a broader qualitative exploration of the experiences of social workers with disabilities in the fields of both education and employment. This particular analysis examined opportunities and barriers to obtaining social work employment by social workers with disabilities. Using the perspective of the social model of disability, which recognizes that many of the limitations regarding disability rest not with the disabled individual but within the societal lack of accommodation and acceptance of disabilities (Shakespeare 2006), this study viewed disability status as a personal characteristic that may or may not require accommodations for employment, rather than a potential limitation to employment. Furthermore, in using a social justice interpretive lens 
(Mertens 2003), the study was designed to elicit the perspectives of the social workers themselves, as professionals with disabilities.

The study proposal was fully reviewed and approved by the two institutional review boards of the universities the authors represent. Care was taken for the protection of all study participants to ensure voluntary participation, obtain informed consent, maintain participant confidentiality, and attend to ethical consideration throughout the research process. The research team consisted of three social workers with extensive personal, practice, and research experience with disabilities. The project was funded via departmental funding at each of the universities with which the authors are affiliated.

\section{Data collection}

$\underline{\text { Recruitment }}$

Researchers recruited participants via an email list of participants from a prior study who had indicated interest, and by using social media posts. The social media posts were placed on a page for social workers to share and seek resources, and on the pages of two universities with sizeable social work programs in a large metropolitan area of a Midwestern state. Posts were reposted weekly until no new potential participants emerged for two consecutive weeks. Eligibility criteria included having completed a Bachelor of Social Work (BSW) or a MSW degree, or both, and self-identifying as having a disability. A total of 22 people expressed interest in study participation. There were a total of 14 study participants in this inquiry, as one participant in the larger study was a student who had not yet sought employment and seven others did not schedule an interview. 


\section{$\underline{\text { Participants }}$}

All 14 of the study participants identified themselves as Caucasian females. Participants ranged in age from 23 to 49 years, with a mean age of 33.5 years. About half of the participants had both their BSW and MSW degrees $(n=8)$, while four had only their MSW and two had only their BSW. Participants reported between one and five diagnoses each. Five participants reported a mental health diagnosis (bipolar disorder, depression, generalized anxiety disorder, posttraumatic stress disorder), four participants reported disabilities that have physical limitations (cerebral palsy, chronic pain, chronic fatigue, fibromyalgia, cardiomyopathy), two participants reported a sensory limitation (visual and hearing impairment), and seven participants reported a neurological disorder (attention deficit disorder/attention deficit hyperactivity disorder, epilepsy, narcolepsy, Asperger's/autism spectrum disorder, non-verbal learning disorder, specific learning disorder, and dyslexia).

Interviews

One of two researchers interviewed the participants. A semi-structured interview guide was developed for use in the interviews to draw out the experiences of social workers with disabilities regarding professional employment. This guide was developed collaboratively by all three researchers, drawing from their personal and professional experiences with a disability as social workers, employees, colleagues, managers, and instructors/professors. Participants were asked to discuss their experiences with the job search, interviewing and hiring process, employment, perceived accommodations needed and actual accommodations received, formal and informal supports received, as well as thoughts and feelings about challenges and opportunities of being a social worker with a disability. Interviews averaged 60 minutes in length, and occurred either in person or over the telephone, based on the preference of the 
participant. Interviews were audio-recorded and transcribed verbatim by an external transcription service.

\section{Data analysis}

The three authors initially worked independently in analyzing the interview transcripts, identifying themes that emerged from the data using an open coding process as described by Creswell (2013). The researchers then discussed the identified themes to obtain inter-coder agreement, and inductively developed four main categories of themes based on notable patterns that emerged. Following the identification of the broad themes, the researchers then went back to the data to search for data elements and potential subthemes under the main categories, while remaining open to the identification of new themes and categories. A fifth theme was identified, and others were revised in this process. The researchers continued to rework the themes and categories until all parties were satisfied that the thematic framework captured the essence of the interviews. In an attempt to protect for bias in interpretation of the data, the researchers reflected on personal and professional experiences with disabilities, as university faculty, social work employees, and managers. Parties discussed these experiences and potential biases and assumptions throughout the research process.

\section{Findings}

Through semi-structured individual interviews, participants were asked about the nature of their disability and needed employment accommodation, their experiences as social workers seeking employment, and their experiences working as social workers. For many within our sample, disability has been challenging to navigate and negotiate in social work employment. Challenges were experienced in the pursuit of employment, the need for accommodation, feeling 
accepted and supported, and being able to fulfill one's potential as a social worker. These challenges contributed to varying degrees a sense of disappointment in the social work profession and social work employment. However, there were also clear examples of what works and what could be better to ensure the inclusion of qualified social work professionals with disabilities in the workforce. In the course of data collection and analysis, five themes emerged across participants regarding their social work career and employment experiences: anticipation and experience of hiring discrimination, accommodation confusion, disability makes one a better social worker, disappointment with the social work profession, and employment could be different (and better).

\section{Anticipation and experience of hiring discrimination}

The job search process contained many disability-related challenges for gaining social work employment including decisions about disability disclosure, being denied job opportunities, uncertainty about disability rights and responsibilities, and opting for underemployment due to these challenges and discrimination. Some aspects of this experience were different for those whose disability was invisible versus those with a visible or apparent disability.

Fear of and frustration with being denied employment

Fear of being denied employment due to disability was more common for those with invisible disability whereas frustration with actually being denied employment was more commonly associated with visible disability. Those with invisible disabilities described defensive non-disclosure of their disabilities: one participant reported of job interviews, 'I never disclose. I always go into those as positively as I can, you know, thinking, No fear. No fear. Just be yourself and, you know, answer the questions as honestly as you can and go from there.' Similarly, another participant reflected protective non-disclosure, reasoning 'who wants a social worker 
who can't hear?' A few participants with invisible disabilities who chose to disclose partially or fully about their disability at the interview did so for mixed purposes: to show the strength of their experience, the need to engage the accommodations process immediately, fear of having their disability-related physical or interpersonal presentation misinterpreted, and a desire to be accepted and chosen as they were.

Without the choice of disclosure, those with visible disabilities expressed frustration with not being given an opportunity. One participant stated:

If someone out there would give me a chance to do the job, I feel like I could, but if no one is going to give me a chance to do it, there's no way I'll ever be able to do it. I'll never be able to prove to anybody that I can do it.

\section{$\underline{\text { Insufficient rights knowledge }}$}

Some participants reported not knowing how to interpret job 'requirements' in a job description or posting; not knowing whether this was an exclusionary criterion or open to accommodation. A participant with a visible disability expressed confusion about what 'essential' work tasks and reasonable accommodations were; 'essential' and 'reasonable' are the specific language of the ADA. In this situation, she had been denied employment at the initial interview point due to an inability to perform a job task, yet she had not been offered an opportunity to discuss accommodation. In contrast, another participant with a visible disability pursuing a job that required a driver's license was told in the course of the interview that use of public para-transit was acceptable. Interestingly, a driver's license continued to be specified as a requirement for this position despite the employer hiring this and another social worker who used public para-transit. 
A few participants utilized formal disability-related support services in their pursuit of employment, and guidance received about rights and responsibilities was mixed. One participant was told, “"Apply. Apply no matter what.” .... [A]ll they've been telling me is, "Apply for the job, and if they really like you, they'll figure something out." Another participant was advised that, despite having completed both a BSW degree and a MSW degree, there would likely be nothing she could do in social work following their assessment of the limitations of her disabilities.

\section{$\underline{\text { Underemployment }}$}

Rather than engaging in the job search process, some participants chose to accept and stay with jobs below their level of training and competence for multiple reasons that reflect job search challenges. Some chose to remain rather than seek new employment for affirming reasons: feeling accepted in the current workplace, having been accepted by the employer after essentially being 'vouched' for through referral to the job by another employee, staying with the job allowed time to gain experience with both coping and adaptation skills, and believing their disability experience was of value to the current employer or coworkers. One participant reported her choice to remain in her job despite having completed her MSW:

I disclosed it to my clinical supervisor, and I shared it with others, and I think they're very accepting of me. And I think what matters - you know, even though the pay is not the greatest and I'm not doing a lot of social work stuff, I think the very fact that it's the first time I'm accepted for who I am goes a long way. 
For others, this choice to not pursue employment at their level of qualification due to job search challenges and disability reflected a foreclosure on possibility rather than prioritizing a satisfying social work career. A participant shared about her pursuit of suitable employment, [T] hen it became about trying to find a job that I could tolerate in social work out of necessity ... then it became what types of jobs are going to be able to allow me the flexibility that I need and not be super stressful.

\section{Accommodation confusion}

Once employed, most aspects of employment accommodation revealed within this sample a theme of confusion for both participants and their employers: confusion in the definition of accommodation and responsibility for accommodating, the felt burden of accommodation, and what appears to be a pervasive failure of imagination. Participants reported a wide variety of needed accommodation to their job or workplace environment to be successful in employment, including use of the public/para-transit system, reduced work hours, caseload adjustments regarding client service needs, adapted client group activities, a rolling briefcase, flexible scheduling or worksite location, a keyboard riser and adapted keyboard, leave/time away from work for physical rehabilitation, sick time for mental health episodes, an adapted telephone, noise/distraction management, and a scribe and/or voice-activated software and reading software. Participants identified these as necessary, yet not all of these needed accommodations were sought or fulfilled due to challenges understanding accommodation, felt burden, and difficulty reconceptualizing how a social work job could be done. 


\section{Defining accommodation and responsibility}

Clear and specific understanding of accommodation and the process of seeking accommodation was not common within this sample. The lack of clarity began at the point of understanding what is considered an ADA allowed accommodation. One participant with a psychiatric disability reported having had no accommodations in many years of social work employment; she reported that this did not mean accommodations were not needed, but she did not believe there were any available for her disability. Although others recognized their ADA disability, they similarly did not know what accommodation was possible:

So it was working with the doctors ... and my neurologist and everybody, who were giving me suggestions then after I had already been involved in all of [these employment struggles] for nine months, but they said, well, it might be helpful if you get this kind of accommodation, and it might be helpful if you get this, and I said, 'Oh, I can ask for that? I can do that?'

Some reported not asking for needed accommodation due to not knowing the process. One participant reported self-accommodating for many years in multiple social work jobs but recognizing that was no longer adequate to be successful; however, she was struggling to know what to do:

So I know I need to look into those things, but I kind of keep dragging my feet, if that makes any sense. I'm just maybe nervous about what the response will be, you know, or finding out something that ... like I don't know enough about the law, like would I have had to disclose when I applied for the job, in order to get accommodations? Like different things like that. I don't know those answers, so I guess I'm nervous as to what they're going to be. 
Others continued to self-accommodate as well due to fearing consequences of disclosure of disability or feel discouraged by the multiple steps they thought were required to gain accommodation. Some participants also sought and received adjustments without recognizing it as accommodation for an ADA disability, such as requesting time off for appointments or being able to use an alternative workspace.

Participants also reported that employers and supervisors had limited understanding of accommodations, rights, and responsibilities. Employers, when informed of the need for accommodation for an ADA disability, seemed in the perspective of some participants to not know what to do to accommodate, and appeared to have no experience working with a person with a disability:

I think there just needs to be more awareness of accommodations, if that makes sense, or just more training in general of how to accommodate a person with a disability and brainstorm different ways that they can perform their job, without just saying, 'Oh, well, we're not really sure where to go from here, so we're just going to give up on you.'

Others experienced feeling pressured to disclose more detail about their disability than they felt was necessary to prove need, and one expressed fear of retaliation if she was to be forced to disclose more detail. In contrast, some social workers perceived that their employers ignored obvious needs due to fears of not knowing what to say and how to talk about accommodation needs with employees. 


\section{Felt burden of accommodation}

The work environment in which accommodation is negotiated and provided could create additional strain for a social worker with disabilities. Several participants with accommodations or who sought informal 'flexibility' within job tasks felt a frequent tension in trying to balance their needs against the job or organization's needs. It was not uncommon to give in to the felt pressure to work beyond one's limits: 'I think that we're so set with like the task of saving the world and dealing with the hardest to serve populations, ... it kind of makes me feel like, well, what do I have to complain about.' Some felt burdened by the knowledge that their accommodations often in practice shifted additional tasks to coworkers or impacted client care. Participants felt this burden despite awareness that this was a system or management issue and not an individual failing. The right to an approved accommodation such as reduced time without systematic consideration called into question this right, as one participant stated:

[I]f you cannot get it, that makes that right superfluous, and I feel like if you're - I mean, I have had conversations with my employer where he says like do this, do this, take time, take this, and it's like, well, can I get any assistance with my workload, and then there's no help given there, so, again, I feel like it's saying you can do this, but not actually creating the environment where it is possible.

One participant highlighted the negative culture that can exist around addressing one's needs: 'So it's an interesting phenomenon, because we are told that we need to practice self-care over and over and over again, but then sometimes, when we ask for it, it's like we're kind of shamed for it.' 


\section{$\underline{\text { Failure of imagination }}$}

Many of the experiences of pursuing, acquiring, and maintaining employment reflected a failure of imagination regarding accommodation; a limited capacity to reconceptualize how a social work job can be successfully performed. Participants in some cases expressed that they needed to be allowed to figure out how to be successful in a new social work job. Others expressed the need to be able to 'think outside the box' or to be able to talk through what they needed to be successful when accommodation options were not immediately apparent. Participants expressed frustration that there was a lack of greater employer flexibility in this problem-solving process and that there was no sense of commitment to being given a chance to be successful. One reflected upon a prior failed employment effort:

I did not think that was reasonable at all, and I don't think they tried hard enough, to be quite honest. And any options that I threw out there, it was, 'Well, we can't really do that, because it's not in the budget.'

In another instance, this participant reported that no efforts to accommodate were made, and her employment was terminated.

\section{Disability makes one a better social worker}

For many participants, part of the draw to social work as a profession related to their own experiences with disability, challenge, and success, and across the board participants expressed the belief that disability made them a better social worker. This theme was a common participant identification of disability as an individual asset as a professional social worker. This asset enabled greater understanding of client experiences of limitations and needs through empathy, 
sensitivity, and intuitive capacity. This asset also enabled greater patience and acceptance of clients, and through one's own experience of having successfully overcome challenges, being able to recognize clients' unique qualities beyond disability to empower client success. With this asset for many came a sense of responsibility and commitment to aid others as a social worker: I feel like I work really well with all of my clients, because I can really get down on their level and meet them where they're at, because I can kind of understand, in a way, of where they are at, realistically, and when they're explaining different things about their own disabilities, I can relate to that in my own way and I can work really hard on - I was given the resources and the support because I was lucky enough to get that, and now I'm that person's support to give them those resources. Now it's my job to follow through on that, and it gives me a lot of motivation and responsibility that I'm willing to have because of those experiences.

\section{Disappointment in the social work profession}

In reflecting upon their experiences as professional social workers with disabilities, these participants shared a sense of disappointment in the social work profession not living up to its values regarding employment of people with disabilities. As already noted, many had been drawn to social work with the expectation of inclusion and welcome based upon the core values of the profession:

$[\mathrm{M}] \mathrm{y}$ perception of social work is that we're people who help other people to become more independent and be successful in the community, and I didn't - when I first started, I was very hopeful that people were going to be able to do that for me when I was starting to find a job, and then the reality is like people are just not - they either don't have a lot 
of experience working with employees with disabilities, or they're just not willing to be accommodating.

Many reported surprise and disappointment to have not found openness and acceptance within social work employment:

I think that if a place - for a profession that says they pride themselves on working with people, all types of people, I would wish that they be a little more open and not so set back in a different time period - that's all I can say - of not hiring people. Just because I can't do one thing doesn't mean I can't do other stuff. You know, just because I can't drive doesn't mean I can't do, you know, a whole myriad of other things to help people, you know.

Several participants also reported the harm of both direct and indirect stigma from coworkers and employers. They experienced this harm in observing other employees portrayed negatively and isolated due to disability and themselves feeling colleagues responded to them differently once their diagnosis was disclosed, such as not being able just to have a bad day like everyone else without it being about their disability. Others were subjected to mocking or harassment by coworkers regarding accommodations. Additionally, participants felt silenced by how colleagues referred to client disabilities in negative and judgmental ways, such as saying of a client 'oh, this patient is just making this crap up' or being dismissive of the impact of a client's diagnosis. As a result, one participant reported 'so you just learn how to kind of suck it up and perpetuate the stigma even more,' and for another 'it's come to the point where I'm looking at getting out of the field of social work altogether, which is disappointing to me, because I do love being a social worker. I just don't know what else to do.' 


\section{Employment could be different (and better)}

Participants' successes and suggested solutions for employment of social workers with disabilities demonstrated the potential for improvement within the profession. Current success reflected the value of workplace flexibility, a sense of we are all in this together, and employers having both knowledge about accommodation and valuing those with disabilities as an asset to the work. A clear understanding of employment rights and responsibilities regarding accommodation coupled with a system to address this universally was beneficial. Several participants had jobs in which there was a systematic process of asking about the need and negotiating possible ADA disability accommodations. In one case, human resources staff asked this in the first interview, whereas in another case the employer conducted a separate interview focused solely upon the job description and possible need for accommodation. Being able to problem-solve job task challenges with a supervisor in an informal and ongoing manner was helpful and empowering. Having a supervisor who had shared experience of disability accommodation was also helpful and felt both supportive and encouraging. A work culture that communicates 'we are all in this together' rather than one of fear and isolation allowed for greater flexibility, innovation, and ingenuity in accommodation to better balance needs and strengths of not only the employee with a disability, but the team.

Participants shared many ideas shaped by their experiences to aid in the inclusion of qualified professional social workers. One suggestion was that schools of social work could play a more active role by incorporating disability learning within diversity/cultural competence training as well as in the development of social work identity. Addressing stigma in ways that are effective to change both attitude and behavior was recommended, being mindful not merely to 
stir up fear of being stigmatized in the workplace. More resources and better access to resources and support was suggested both in school as well as in the workplace. For schools:

I wish that the graduate program would do a lot better job of screening people ... not screening to exclude, but screening for who are the people that are highest at risk ... identifying them, not for shame and stigma purposes, but for having alongside them a colleague and a peer professional that has also struggled with that same issue. I think it would be a lot less isolating.

Additionally, 'having appropriate resources for [students] for learning good coping and stress management' was suggested.

Participants also gave workplace suggestions. These included for employers to consider for all employees clarity about the support and benefits to ensure that adequate accommodations are available. Also suggested was building a culture that affirms the use of formal supports and to nurture the development and use of workplace support systems when an employee is struggling. Participants suggested a work culture valuing both problem-solving and self-care - 'I feel like it should be, like I said with the self-care piece, a lot easier than it is' and:

... I feel like in any helping profession, you should be able to do things at your own pace so that you don't burn out, because I know that I can only handle so much and that I am a valuable employee, and if they just give me a little bit of wiggle room to be able to figure out what I can and can't do, it will be a lot better in the long run than just saying, 'Deal with it and push through.' 


\section{Discussion}

This study was a small, exploratory inquiry to begin to understand more about people with disabilities within the social work workforce from their perspective. Within a critical social work practice framework, this study seeks to explore the participation of people with disabilities as peer colleagues. The challenge of equal opportunity in social work employment for qualified social workers with disabilities is evident in the findings of this study. That opportunity is possible is evinced as well, although this felt more like an exception and a surprise by those given it. Governmental guidance regarding the ADA and employment in its provision of definitions and examples of essential versus marginal job functions, reasonable accommodation versus undue hardship, description of a request for accommodation, and necessary ADA disability disclosure reflects the potential of a much more nuanced and enlarged opening for successful social work employment than our participants' experience reveals.

Disability stigma, the detrimental effect of a negative perception of people with disabilities, describes how negative attitudes and beliefs impact behavior in the interaction between people with disabilities and employers, collectively leading to lower rates of employment (Green et al. 2005). This experience of disability-related stigma and self-stigma were evident in these findings. Self-stigma or internalization led to participants not seeking needed accommodation or support and limiting activation of one's full professional potential. Social workers internalize the stigma in part due to the feeling that clients either have more significant issues, or out of not wanting to compromise client care due to their own needs. The experience of public stigma may be better framed as discrimination in employment, experienced by these participants as failure to be hired, denial of accommodation, a work environment evidencing hostility to disability, and termination of employment. 
Ambivalence within the profession regarding the employment of people with disabilities is suggested in these findings. Respondents strongly endorsed the sentiment that people with disabilities add value and ought to be represented in the social work profession. It would seem logical to find people with disabilities drawn to the social work profession due to its values or as a profession where they may have been served; however, they are not sought. Within social work, can our profession conceptualize participation and inclusion of people with disabilities to multiple identities: client, citizen, and colleague? The social work field allows the opportunity of multiple roles and contexts for trained professionals enabling potential broad opportunity for people with disabilities to find employment fit for both interest and ability.

\section{Diversity within the social work profession}

Our participants reflect, for the social work profession, concern that social work has more work to do to embody its commitment to empowerment and advocacy for people with disabilities, recognized amongst marginalized and oppressed groups. In the United States, the National Association of Social Workers' National Committee on Racial and Ethnic Diversity revised in 2015 the Standards and Indicators for Cultural Competence in Social Work Practice; disability was added as an aspect of diversity, broadening the definition of culture (NASW 2015). Cultural competence standards include a Diverse Workforce standard with both social worker and organizational indicators for cultural competence (2015, 40-41). Our participants, although not representative of racial and gender diversity, demonstrate indigenous insight into how this standard may be applied regarding disability. Competence may be enhanced by utilizing the lived wisdom of professionals with disabilities in specific work settings to develop knowledge and flexibility in innovative accommodation. Sheridan, White, and Mounty 
$(2010,9)$ describe an effort of 'collaboration, persuasion, and education' between employers and social workers who were deaf and hard of hearing to aid full workplace inclusion of these social workers.

\section{Social service employers}

Social work employers may first need to establish a more transparent and intentional effort for the development of this diverse segment of the workforce. This effort could mean the development of specific hiring and recruitment policies and implementation strategies in support of a diverse workforce including people with disabilities. Within this study was shown an example that the successful hiring and accommodation of one social worker with a disability quickly led the additional hiring of another. Further, reflecting earlier scholarship (Neely-Barnes, McCabe, and Barnes 2014; O’Brien and Brown 2009; Pardeck 1998), workplace-specific critical examination of essential and marginal job functions is needed, as well as investigation of the broad possibilities for accommodation, to both recognize and value multiple pathways of accomplishing these tasks to serve clients in order to support sustained employment and opportunities for advancement for a diverse workforce. Moreover, efforts to reduce stigma about needing and requesting accommodations and promoting a teamwork atmosphere could reduce the internalized burden that people with disabilities have felt regarding shifts in workloads and specific job duties.

\section{Strengths and limitations}

The primary limitation of this study is that all of the participants were Caucasian females, despite targeted efforts to recruit males and social workers of color. Furthermore, with only 14 participants from one state in the Midwest region of the United States, findings may not 
represent the experiences of social workers with disabilities in other regions and the complexities of identifying as a person of color with a disability. However, given the geographic area that the study took place in, a state with an $80 \%$ non-Latino Caucasian population (U.S. Census Bureau 2017), the participants represent the majority racial group in a profession where over $85 \%$ of its workforce is female (Salsberg et al. 2017). Despite limitations of lack of race and gender diversity, participants identified with a variety of disability diagnoses and age/stage emergence of disability, adding to the richness and depth of the data. Furthermore, as this inquiry was designed to bring forth the experiences of social workers with disabilities from their perspectives, this study adds to the existing literature in this area and emphasizes the social justice implications for the profession of social work in employing and accommodating people with disabilities.

\section{Conclusions}

This study only begins to inform our understanding of people with disabilities in the professional social work workforce. The study raises questions about the professional commitment to empowerment and inclusion of people with disabilities, not only as clients and citizens but as colleagues. This study also underscores the value and potential of supporting a diverse workforce in social work.

\section{Disclosure statement}

No potential conflict of interest was reported by the authors. 


\section{References}

Baron, S., R. Phillips, and K. Stalker. 1996. “Barriers to Training for Disabled Social Work Students.” Disability and Society 11 (3): 361-377.

Burkhauser, R. V. and M. Daly. 2011. The Declining Work and Welfare of People with. Disabilities: What Went Wrong and a Strategy for Change. Washington, DC: AEI Press.

Creswell, J. W. 2013. Qualitative Inquiry \& Research Design: Choosing among the Five Approaches, 3rd ed. Thousand Oaks, CA: SAGE Publications, Inc.

Cook, J. A. 2006. "Employment Barriers for Persons with Psychiatric Disabilities: Update of a Report for the President's Commission.” Psychiatric Services 57 (10): 1391-1405.

Fevre, R., A. Robinson, D. Lewis, and T. Jones. 2013. "The Ill-treatment of Employees with Disabilities in British Workplaces.” Work, Employment and Society 27 (2): 288-307.

Flanagan, T., F. J. Benson, and F. Fovet. 2014. "A Multi-perspective Examination of the Barriers to Field-placement Experiences for Students with Disabilities.” Collected Essays on Learning and Teaching 7 (2): 157-162.

Foster, D., and P. Fosh. 2010. “Negotiating 'Difference': Representing Disabled Employees in the British Workplace.” British Journal of Industrial Relations 48 (3): 560-582.

Green, S., C. Davis, E. Karshmer, P. Marsh, and B. Straight. 2005. "Living Stigma: The Impact of Labeling, stereotyping, separation, status Loss, and Discrimination in the Lives of Individuals with Disabilities and Their Families." Sociological Inquiry 75 (2):197-215. 
Hall, J. P., A. Shartzer, N. K. Kurth, and K. C. Thomas. 2017. "Effect of Medicaid Expansion on Workforce Participation for People with Disabilities.” American Journal of Public Health 107 (2): 262-264.

Hernandez, B., C. Keys, and F. Balcazar. 2000. "Employer Attitudes toward Workers with Disabilities and Their ADA Employment Rights: A Literature Review.” Journal of Rehabilitation 66 (4): 4-16.

Kaye, H. S., L. H. Jans, and E. C. Jones. 2011. "Why Don’t Employers Hire and Retain Workers with Disabilities?” Journal of Occupational Rehabilitation 21 (4): 526-536.

Kennedy, J., and E. Blodgett. 2012. "Health Insurance-motivated Disability Enrollment and the ACA.” New England Journal of Medicine 367 (12): e16.

Lengnick-Hall, M. L., P. M. Gaunt, and M. Kulkarni. 2008. “Overlooked and Underutilized: People with Disabilities Are an Untapped Human Resource.” Human Resource Management 47 (2): 255-273.

Levy, A. R., B. K. Bruen, and L. C. Ku. 2013. "The Potential Employment Impact of Health Reform on Working-age Adults with Disabilities.” Journal of Disability Policy Studies 24 (2): $102-112$.

Livermore, G. A., and N. Goodman. 2009. A Review of Recent Evaluation Efforts Associated with Programs and Policies Designed to Promote the Employment of Adults with Disabilities. Princeton, NJ: Mathematica Policy Research. 
Mackelprang, R., J. Ray, and M. Hernandez-Peck. 1996. "Social Work Education and Sexual Orientation: Faculty, student, and Curriculum Issues.” Journal of Gay \& Lesbian Social Services 5 (4): 17-32.

Mackelprang, R. W. 2010. “Disability Controversies: Past, present, and Future.” Journal of Social Work in Disability \& Rehabilitation 9 (2-3): 87-98.

Mackelprang, R. W., and R. O. Salsgiver. 2015. Disability: A Diversity Model Approach in Human Service Practice, 3rd ed. Chicago, IL. Lyceum Books, Inc.

McLaughlin, M. E., M. P. Bell, and D. Y. Stringer. 2004. "Stigma and Acceptance of Persons with Disabilities: Understudied Aspects of Workforce Diversity." Group and Organizational Management 29 (3): 131-145.

Matt, S. B. 2008. "Nurses with Disabilities: Self-reported Experiences as Hospital Employees.” Qualitative Health Research 18 (11): 1524-1535.

Mercer, S., P. Dieppe, R. Chambers, and R. MacDonald. 2003. "Equality for People with Disabilities in Medicine.” BMJ 327 (7420): 882.

Mertens, D. M. 2003. "Mixed Methods and the Politics of Human Research: The Transformative Emancipatory Perspective.” In Handbook of Mixed Methods in Social and Behavioral Research, edited by A. Tashakkori and C. Teddlie, 135-164. Thousand Oaks, CA: SAGE Publications, Inc. 
Mik-Meyer, N. 2016a. 'Disability and 'Care': Managers, Employees and Colleagues with Impairments Negotiating the Social Order of Disability.” Work, Employment and Society 30 (6): 984-999.

Mik-Meyer, N. 2016b. "Othering, Abelism and Disability: A Discursive Analysis of Coworkers' Construction of Colleagues with Visible Impairments." Human Relations 69 (6): 1341-1363.

NASW. 2015. Standards and Indicators for Cultural Competence in Socia Work Practice. http://www.socialworkers.org/practice/standards/PRA-BRO-253150-CCStandards.pdf

Neely-Barnes, S. L., H. A. McCabe, and C. P. Barnes. 2014. "Seven Rules to Live by: Accommodations in Social Work Education and the Field." Journal of Social Work in Disability and Rehabilitation 13 (4): 279-296.

O’Brien, G. V., and M. S. Brown. 2009. "Persons with Mental Illness and the Americans with Disabilities Act: Implications for the Social Work Profession.” Social Work in Mental Health 7 (5): 442-457.

Orzolek-Kronner, C. 2007. “The Impact of Sight Loss in Social Work Practice.” Journal of Social Work in Disability \& Rehabilitation 6 (1-2): 157-177.

Pardeck, J. T. 1998. Social Work after the Americans with Disabilities Act: New Challenges and Opportunities for Social Service Professionals. Westport, CT: Auburn House. 
Salsberg, E., L. Quigley, N. Mehfoud, K. Acquaviva, K. Wyche, and S. Sliwa. 2017. Profile of the Social Work Workforce. Washington, DC: The George Washington University Health Workforce Institute.

Samant, D., M. Soffer, B. Hernandez, M. Adya, O. Akinpelu, J.

M. Levy, E. Repoli, M. Kramer, and P. Blanck. 2009. "Corporate Culture and Employment of People with Disabilities: Role of Social Workers and Service Provider Organizations." Journal of Social Work in Disability and Rehabilitation 8 (3-4): 171188.

Scheid, T. L. 2005. "Stigma as a Barrier to Employment: Mental Disability and the Americans with Disabilities Act.” International Journal of Law and Psychiatry 28 (6):670-90.

Shakespeare, T. 2006. “The Social Model of Disability.” In The Disability Studies Reader, edited by L. J. Davis, 2nd ed., 197-204. New York: Routledge.

Sheridan, M. A., B. J. White, and J. L. Mounty. 2010. "Deaf and Hard of Hearing Social Workers Accessing Their Profession: A Call to Action.” Journal of Social Work in Disability \& Rehabilitation 9 (1): 1-11.

Shier, M., J. R. Graham, and M. E. Jones. 2009. "Barriers to Employment as Experienced by Disabled People: A Qualitative Analysis in Calgary and Regina, Canada.” Disability and Society 24 (1): 63-75.

Sommers, B. D., and A. M. Epstein. 2013. "US Governors and the Medicaid Expansion No Quick Resolution in Sight.” New England Journal of Medicine 368 (6): 496-499. 
Stapleton, D. C., B. L. O’Day, G. A. Livermore, and A. J. Imparato. 2006. "Dismantling the Poverty Trap: Disability Policy for the Twenty-first Century.” The Milbank Quarterly 84 (4): 701-732.

U.S. Census Bureau. 2017. Quick

Facts. https://www.census.gov/quickfacts/fact/table/MN/PST045217

U.S. Department of Labor. 2017. Persons with a Disability: Labor Force Characteristics 2016. USDL-161248. https://www.bls.gov/news.release/pdf/disabl.pdf

U.S. Department of Labor, Office of Disability Employment Policy. 2008. Survey of Employer Perspectives on the Employment of People with Disabilities: Technical Report. http://www.dol.gov/odep/research/SurveyEmployerPerspectivesEmploymentPeo plDisabilities.pdf

U.S. Department of Labor, Office of Disability Employment Policy. (2018a). Accommodations. https://www.dol.gov/odep/topics/Accommodations.htm

U.S. Department of Labor, Office of Disability Employment Policy. (2018b). Frequently Asked Questions. http:/www.dol.gov/odep/faqs/general.htm

Valle, J. W., S. Solis, D. Volpitta, and D. J. Connor. 2004. "The Disability Closet: Teachers with Learning Disabilities Evaluate the Risks and Benefits of 'Coming Out'.” Journal Equity \& Excellence in Education 37 (1): 4-17.

Wahl, O. 1999. "Mental Health Consumers' Experience of Stigma." Schizophrenia Bulletin 25 (3): 467-478. 
Whitaker, T., T. Weismiller, and E. Clark. 2006. Assuring the Sufficiency of a Frontline Workforce: A National Study of Licensed Social Workers. Executive Summary. Washington, DC: National Association of Social Workers.

Wilson-Kovacs, D., M. K. Ryan, S. A. Haslam, and A. Rabinovich. 2008. "Just Because You Can Get a Wheelchair in the Building Doesn't Necessarily Mean That You Can Still Participate': Barriers to Career Advancement of Disabled Professionals.” Disability and Society 23 (7): 705-717. 